\title{
Body Image Perception and Self-esteem During Pregnancy
}

\section{Sema Inanir', Bulent Cakmak², Mehmet Can Nacar², Askin Evren Guler ${ }^{3}$, Ahmet Inanir ${ }^{4}$}

\begin{abstract}
Objectives: The aim of this study is to examine the change in body image perception (BIP) and evaluate self-esteem levels during pregnancy.

Material and Methods: This study includes totally 180 females having similar demographic features, i.e. 30 non-pregnant (control group) and 50 pregnant women from each trimester (first, second and third trimester groups) at an Obstetrics Outpatient Department of a university hospital. BIP and self-esteem scores have been compared among the groups. Data relating to all participants have been obtained by using socio-demographic data form, body image scale and Rosenberg Self-Esteem Scale (RSES).

Results: All demographic features have been found to be similar among the groups. The body mass index (BMI) was higher in the third trimester of pregnancy compared to other groups; whereas BIP was significantly worse in the third trimester group compared to the first trimester and control groups $(P<.05)$. There was a negative correlation between trimesters of pregnancy and BIP $($ Rho $=$ -0.221; $P=.003)$. Self-esteem was detected at a relatively higher level in first trimester group compared to the second and third trimester groups $(P<.05)$.

Conclusion: BIP levels have declined during the pregnancy period and self-esteem has been observed at a higher level in the first trimester compared to the advanced trimesters of pregnancy.

Keywords: Body image, Perception, Pregnancy, Self-esteem
\end{abstract}

\section{Introduction}

Although pregnancy is a physiological process, physical and emotional changes are experienced in this period. Several alterations in outward appearance, namely weight gain and skin changes occur throughout the entire body during pregnancy (1). Apart from these, certain biomechanical alterations like increased spinal lordosis (2), decreased abdominal muscle strength (3) and an anterior shift in the location of the centre of mass (4) are observed. The incidence of certain psychological disorders increases during pregnancy; the prevalence of anxiety symptoms is around 20\%-25\% and depression rate differs between populations but it is generally around $20 \%(5-7)$.

The body image perception (BIP) is defined as inner expression of the outward appearance of the individual. BIP has a decisive impact on eating behaviours of individuals, level of social anxiety, sexual behaviour, social relationships and emotional state (8). During pregnancy, the BIP may vary due to rapid physical changes occurring in women's bodies $(9,10)$. Body perception is reported to significantly decrease in the early stages of pregnancy compared to pre-pregnancy period (11).

Self-esteem is defined as a perception of individual life style as well as the value attached by the community to the individual owing to his/her past experiences. Individuals with high self-esteem are more creative, successful, healthy, self-confident, assertive and capable of expressing ideas easily and they are largely seen as socially compatible people (12). During pregnancy, self-esteem level may decline as women find themselves feeling fat and less attractive (13). The aim of this study is to compare the perception of body image and self-esteem between the women at different periods of pregnancy and non pregnant women.

\section{Materials and Methods}

One hundred fifty pregnant patients, 50 from each trimester, who applied to the Obstetrics Outpatient Clinic at a university hospital with similar demographic, social and medical features, agreed to join the study. Thirty women with a history of previous pregnancy and similar demographic, social and medical features were included in the study as the control group. Thus, 180 participants and 4 groups; the "control" group, "first trimester" (Trm-1), "second trimester" (Trm-2) and "third trimester" (Trm-3) participated in the study.

All participants of pregnancy groups were evaluated by 
the obstetrician to determine the existence of pregnancy and to assess the gestational age and relevant trimesters before including the participants within this study. The trimesters were considered as follows: the first 14 weeks of pregnancy as the first trimester, between 14-24 weeks as the second trimester, and after 24 weeks of pregnancy as the third trimester. Pregnant women inflicted with systemic diseases, musculoskeletal disorders, psychiatric disorders, those having a history of surgery and aesthetic surgery, smokers, multiple pregnancies and high-risk pregnancies assessed by the obstetrician were not included in the study. Participants consisting the control group were evaluated in respect of non-pregnancy at the present time, having a history of pregnancy and being in the reproductive period. The same exclusion criteria used for pregnancy groups were also applied to the control group. In collecting the data (a) Socio-demographic data form, (b) BIP Scale and (c) Rosenberg Self-Esteem Scale were used. The Face-to-face interview technique was applied in filling the forms.

Socio-demographic Data Form (SDDF): This form was prepared by researchers, and included questions regarding the demographic, social and medical characteristics of women such as age, number of pregnancies and births, body mass index (BMI), duration of marriage, number of people living at home, education level, employment status and economic status of the family.

Body Image Perception Scale (BIPS): This scale was developed by Secord and Jourard, evaluates individual's satisfaction of various parts of human body and body function (14). The Turkish format of the Scale prepared for our country was used in the study (15). The scale consists of 40 items, where the lowest score is 40 and the highest score is 200. Low score means high discontent, while high scores on body image indicate high satisfaction.

Rosenberg Self-Esteem Scale (RSES): This scale was developed by Rosenberg (16). The reliable format of this scale validated for Turkey was used in our study (17). The scale is composed of multiple-choice questions with 12 subcategories and totally 63 questions. The first " 10 " statements of the scale were used to measure self-esteem for the purpose of this study. High scores of RSES were considered as low self-esteem.

Demographical features from SDDF, BIPS and RSES scores were compared among the 4 groups. The Faculty of Ethics Committee approved this study, and all of the participants have accordingly submitted their written consents for taking part in the study. All data were analyzed using the PASW statistics version 18.0 (SPSS, Chicago, IL, USA). The Kolmogorov-Smirnov test was used to determine the normality of distributions of variables. Continuous, non-parametric and categorical variables were presented as mean $\pm \mathrm{SD}$, mean $\pm \mathrm{SD}$ (min-max) and frequency (\%), respectively. Analysis of variance with Dunnett post hoc test in analysis of variance (ANOVA) was used to analyze the differences among groups for the parametric variables. The Kruskal-Wallis test was used to compare the nonparametric variables, and the Mann-Whitney $U$ test was sub- sequently used to assess the differences among the groups. Categorical variables were compared with $\chi 2$ test or Fisher exact test, where appropriate. A value of $P<.05$ was considered to indicate statistical significance.

\section{Results}

There was no difference among the groups for the demographic, social and medical features except for BMI, as shown in Table 1. BMI was found higher in Trm-3 group compared to other groups $(P=.004)$, and there was a positive correlation between the groups and BMI $(\mathrm{Rho}=0.241$; $P=.001)$.

Control group had the highest BIP score, while Trm-3 group had the lowest, as shown in Figure 1. There was a negative correlation between groups and $\mathrm{BIP}(\mathrm{Rho}=-0.221$; $P=0.003)$. BIP scores were significantly lower in Trm-3 group compared to Trm-1 and control groups $(P<.05)$ (Figure 1). Lower self-esteem scores were detected in Trm-1 group compared to Trm- 2 and 3 groups $(P<.05)$, but there was no significant difference among control, Trm-2 and Trm-3 groups (Figure 2). No correlation was found between self-esteem and the groups $(P>.05$; Table 2 ). There was no correlation between BMI and self-esteem or BIP $(P>.05)$, as shown Table 2.

\section{Discussion}

BIP is a dynamic concept that includes subjective perception. It begins to develop from infancy; particularly gains prominence during adolescence and changes and develops lifelong depending on the individual's own body (18). In women, BIP changes at different stages of life such as puberty, pregnancy and menopause due to structural, functional, hormonal and alterations in the appearance (19-21). Changes occurring in the bodies of women during pregnancy may lead to the feeling of bulkiness, clumsiness, ugliness, and unattractiveness. As a result of these changes, self-confidence, self-esteem and BIP of women may decline and may be adversely affected (22). In our study, BIP was found to have declined as from the first trimester, and the lowest level of BIP was detected in pregnant women at the third trimester. When trimester of pregnancy rises, reduction in BIP level is found to be significant. As it is known, the alterations observed in the body during pregnancy are mostly addressed in the third trimester. Due to weight gaining during pregnancy, women express their concerns and describe themselves as less attractive compared to the non-pregnancy state (23). It has been reported in a study that pregnant women perceived their bodies as unattractive, especially in the third trimester (24). Psychological and physiological changes in the body of the pregnant may sometimes lead to stress (25). In fact, in some cases, as a result of negative perceptions related to body image during pregnancy, women may damage the health of themselves and their babies as they intake insufficient nutrients to lose weight and return to their outward appearance before pregnancy $(9,26)$.

Though BMI was found to be positively correlated with pregnancy period, in our study there was no significant 
Table 1. Distribution of Demographic, Social and Medical Features

\begin{tabular}{|c|c|c|c|c|c|}
\hline \multirow{2}{*}{ Variables } & \multicolumn{4}{|c|}{ Groups } & \multirow{2}{*}{$\boldsymbol{P}$} \\
\hline & Control & Trm 1 & Trm 2 & Trm 3 & \\
\hline Age (y) & $24.8 \pm 5.1$ & $25.4 \pm 4.8$ & $26.6 \pm 5.4$ & $26.7 \pm 4.5$ & 0.293 \\
\hline Number of pregnancy & $\begin{array}{c}2.1 \pm 1.0 \\
(1-4)\end{array}$ & $\begin{array}{c}1.8 \pm 1.0 \\
(1-4)\end{array}$ & $\begin{array}{c}2.0 \pm 1.0 \\
(1-4)\end{array}$ & $\begin{array}{c}1.8 \pm 0.7 \\
(1-4)\end{array}$ & 0.447 \\
\hline Number of birth & $\begin{array}{c}1.6 \pm 1.0 \\
(1-4)\end{array}$ & $\begin{array}{c}1.4 \pm 0.9 \\
(0-4)\end{array}$ & $\begin{array}{c}1.4 \pm 1.2 \\
(0-4)\end{array}$ & $\begin{array}{c}1.2 \pm 0.7 \\
(0-4)\end{array}$ & 0.497 \\
\hline BMI $\left(\mathrm{kg} / \mathrm{m}^{2}\right)$ & $24.6 \pm 3.6$ & $25.1 \pm 4.7$ & $25.3 \pm 3.2$ & $27.7 \pm 4.8$ & 0.004 \\
\hline Marriage duration & $\begin{array}{c}3.8 \pm 2.0 \\
(2-9)\end{array}$ & $\begin{array}{c}3.8 \pm 2.1 \\
(1-9)\end{array}$ & $\begin{array}{c}3.8 \pm 2.2 \\
(2-10)\end{array}$ & $\begin{array}{c}3.6 \pm 2.5 \\
(2-12)\end{array}$ & 0.846 \\
\hline No. of people living at home & $\begin{array}{c}3.6 \pm 0.9 \\
(3-6)\end{array}$ & $\begin{array}{c}3.4 \pm 1.0 \\
(2-6)\end{array}$ & $\begin{array}{c}3.4 \pm 1.2 \\
(2-6)\end{array}$ & $\begin{array}{c}3.3 \pm 0.8 \\
(2-6)\end{array}$ & 0.706 \\
\hline Planned pregnancy ${ }^{a}$ & - & $41(82)$ & $39(78)$ & $38(76)$ & 0.757 \\
\hline \multicolumn{6}{|l|}{ Educational status } \\
\hline Primary school & $14(46.7)$ & $24(48)$ & $20(40)$ & $26(52)$ & \multirow{3}{*}{0.855} \\
\hline High school & $14(46.7)$ & $23(46)$ & $24(48)$ & $21(42)$ & \\
\hline University & $2(6.7)$ & $3(6)$ & $6(12)$ & $3(6)$ & \\
\hline \multicolumn{6}{|l|}{ Working status } \\
\hline Yes & $5(16.7)$ & $7(14)$ & $9(18)$ & $7(14)$ & \multirow[t]{2}{*}{0.932} \\
\hline No & $25(83.3)$ & $43(86)$ & $41(82)$ & $43(86)$ & \\
\hline \multicolumn{6}{|l|}{ Economic status of family } \\
\hline Low & $7(23.3)$ & $11(22)$ & $11(22)$ & $8(16)$ & \multirow{3}{*}{0.933} \\
\hline Medium & $21(70.0)$ & $36(72)$ & $34(68)$ & $39(78)$ & \\
\hline High & $2(6.7)$ & $3(6)$ & $5(10)$ & $3(6)$ & \\
\hline
\end{tabular}

Abbreviations: BMI: body mass index; Trm: trimester.

a Statistical analysis was done among Trm 1, 2, and 3 groups.

Table 2. Correlation Among Groups, BMI, Self-esteem and Perception

\begin{tabular}{llll}
\hline Variables & BMI & Rosenberg & Perception \\
\hline Group & & & \\
$\quad$ Pearson Correlation & 0.241 & 0.079 & -0.221 \\
$\quad P$ value & 0.001 & 0.293 & 0.003 \\
BMI & & & \\
$\quad$ Pearson Correlation & 1 & 0.035 & -0.086 \\
$\quad P$ value & -- & 0.636 & 0.251 \\
\hline
\end{tabular}

Abbreviation: BMI: body mass index.

correlation between the perception of body image and BMI. This result suggests that the decrease in the BIP level is not only related with BMI augmentation, but it is also involved with other changes observed in pregnant women. This arises from the fact that various changes in skin, genital, urinary and gastrointestinal tract may also affect the BIP, apart from the changes of BMI observed during pregnancy.

Changes in self-esteem levels in pregnancy may be impacted by several factors such as the level of education, maternal age, number of previous births, duration of marriage, the income level of the family, regardless of a planned pregnancy (27-31). Therefore, in our study, the patients with similar demographic, social and medical characteristics were compared in terms of self-esteem and BIP. Hence, independent factors on self-esteem and BIP were not included in the study, and only pregnancy periods and control group for self-esteem and BIP were compared. In a study from our country, it has been reported

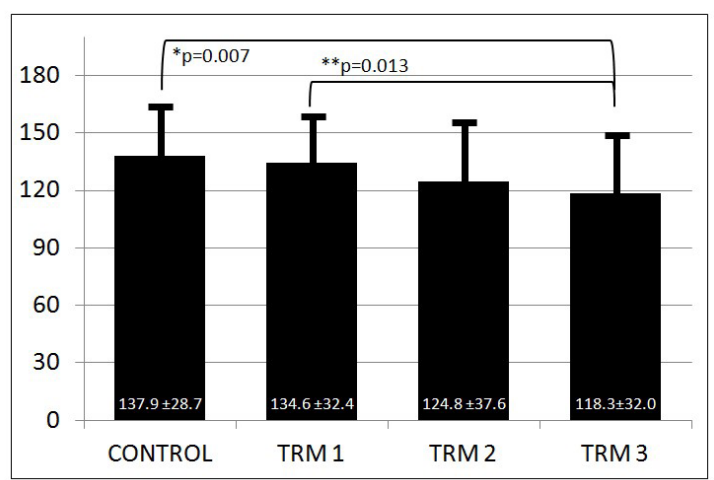

Figure 1. Descriptive statistics (mean \pm SD) for BIP mean score among groups. Trm: trimester. BIP score in Trm-3 was lower than Control $^{*}$ and Trm- $1^{* *}$.

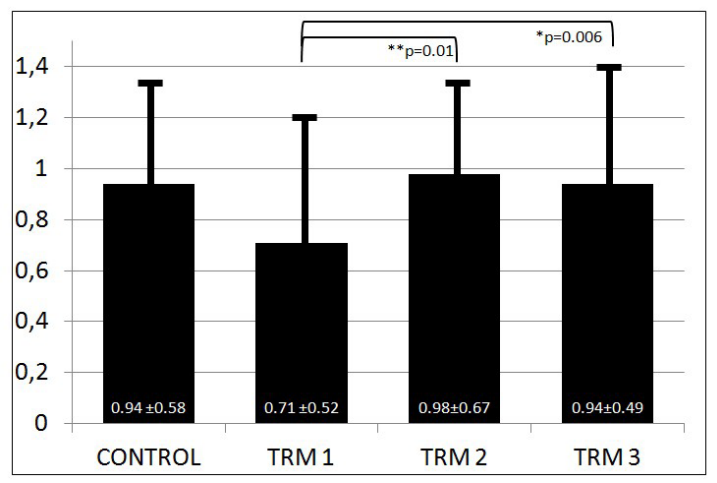

Figure 2. Descriptive statistics (mean $\pm \mathrm{SD}$ ) for self-esteem mean score among groups. Trm: trimester. Self-esteem score in Trm-1 was lower than Trm-2* and Trm-3**. 
that there is no difference among pregnancy trimesters for self-esteem levels (31). However, in our study, apart from the evaluation of only the pregnancy trimesters, women with different demographic and social characteristics such as different maternal age, education level and economic status have been analyzed.

Kamysheva et al (13) reported that pregnant women had low self-esteem since they perceived their bodies as obese and felt less attractive during pregnancy. In our study, there was no correlation between self-esteem and BMI level of the groups. On the contrary, our research has shown that a correlation exists between BMI and BIP.

\section{Conclusion}

This is the first study comparing self-esteem and BIP levels in three trimesters of pregnancy and non-pregnant women. It is also unique as it excludes independent factors affecting body image and self-esteem. The limitation of this study was the creation of the study and control groups from different patients. The study would be better if it was performed as a longitudinal research. Also this is not a great problem because the characteristics of groups were similar in each group. As a result, the BIP during pregnancy is considered to be worse than the non-pregnant period, and it becomes much worse with the progress of pregnancy. We suggest further studies evaluating self-esteem and BIP in same pregnant group with different trimesters which may provide more important information on this topic.

\section{Ethical issues}

The Faculty of Ethics Committee approved this study. All the patients signed an informed consent for participation in the study.

\section{Conflict of interests}

The authors declare no conflict of interests.

\section{Acknowledgments}

The authors declare that there is no acknowledgement.

\section{References}

1. Pacheco L, Costantine MM, Hankins GDV. Physiologic Changes During Pregnancy. In: Mattison DR, ed. Clinical Pharmacology during Pregnancy. San Diego: Academic Press; 2013:5-14.

2. Calguneri $\mathrm{M}$, Bird $\mathrm{H}$, Wright $\mathrm{V}$. Changes in joint laxity occurring during pregnancy. Ann Rheum Dis. 1982;41(12):126-128.

3. Dumas GA, Reid JG, Wolfe LA, Griffin MP, McGrath MJ. Exercise, posture, and back pain during pregnancy. Clin Biomech (Bristol, Avon) 1995;10(2):98-103. doi:10.1016/0268-0033(95)92047-P.

4. Whitcome KK, Shapiro LJ, Lieberman DE. Fetal load and the evolution of lumbar lordosis in bipedal hominins. Nature. 2007;450(7172):1075-1078. doi:10.1038/nature06342.

5. Lee AM, Lam SK, Sze Mun Lau SM, Chong CS,
Chui HW, Fong DYT. Prevalence, course risk factors for antenatal anxiety and depression. Obstet Gynecol 2007;110(5):1102-12. doi:10.1097/01. AOG.0000287065.59491.70.

6. Evans J, Heron J, Francomb H, Oke S, Golding J. Cohort study of depressed mood during pregnancy and after childbirth. BMJ. 2001;323(7307):257-60.

7. Bennett HA, Einarson A, Taddio A, Koren G, Einarson TR. Prevalence of depression during pregnancy: systematic review. Obstet Gynecol. 2004;103(4):698709. doi: 10.1097/01.AOG.0000116689.75396.5f.

8. Cash TF, Fleming EC. The impact of body image experiences: development of the body image quality of life inventory. Int J Eat Disord. 2002;31(4):455-60. doi: 10.1002/eat.10033.

9. Skouteris H, Carr R, Wertheim EH, Paxton SJ, Duncombe D. A prospective study of factors that lead to body dissatisfaction during pregnancy. Body Image. 2005;2(4):347-361.

10. Wingood GM, Diclemente RJ, Harrington K, Davies SL. Body image and African females' sexual health. J Womens Health Gend Based Med. 2002;11(5):433439. doi: 10.1089/15246090260137608.

11. Boscaglia N, Skouteris H, Wertheim EH. Changes in body image satisfaction during pregnancy: a comparison of high exercising and low exercising women. Aus N Z J Obstet Gynecol 2003;43(1):41-45. doi: 10.1046/j.0004-8666.2003.00016.x.

12. Brown JE, Mann L. Decision-making competence and self-esteem: a comparison of parents and adolescents. J Adolesc. 1991;14(4):363-371.

13. Kamysheva E, Skouteris H, Wertheim EH, Paxton SJ, Milgrom J. Examination of a multi-factorial model of body-related experiences during pregnancy: the relationship among physical symptoms, sleep quality, depression, self-esteem, and negative body attitudes. Body Image. 2008;5(2):152-163.

14. Secord PF, Jourard SM. The appraisal of bodycathexis: body cathexis and the self. J Consult Psychol. 1953;17(5):343-347.

15. Hovardaoglu S, Ozdemir YD. Vucut Algisi Olceginin guvenirlik ve gecerlik calismasi / Sizofrenik ve major depresif hastalarin beden imgelerinden doyum duzeyleri (Work of reliability and validity on the body perception questionnaire/Schizophrenic and major depressive patients' body image satisfaction levels). Yuksek lisans tezi, Gazi Universitesi Sosyal Bilimler Enstitusu, Ankara, 1990. (Article in Turkish).

16. Rosenberg M. Society and the Adolescent Self-Image. Princeton, New Jersey: Princeton University Press; 1965.

17. Cuhadaroglu F. Adolesanlarda Benlik Saygisi (Selfesteem in adolescents). Uzmanlık Tezi, Ankara: Hacettepe Universitesi Tip Fakultesi, 1986. (Article in Turkish).

18. Davis DC. The discomforts of pregnancy. J Obstet Gynecol Neonatal Nurs 1996;25(1):73-81. doi: 10.1111/j.1552-6909.1996.tb02516.x. 
19. Grogan S. Body image and health: contemporary perspectives. J Health Psychol 2006;11(4):523-530. doi: $10.1177 / 1359105306065013$.

20. Marshall C, Lengyel C, Utioh A. Body dissatisfaction among middle-aged and older women. Can J Diet Pract Res. 2012;73(2):241-247.

21. Dipietro JA, Millet S, Costigan KA, Gurewitsch E, Caulfield LE. Psychosocial influences on weight gain attitudes and behaviours during pregnancy. J Am Diet Assoc 2003;103(10): 1314-1319. doi: 10.1016/ S0002-8223(03)01070-8.

22. Goodwin A, Astbury J, McMeeken J. Body image and psychosocial well-being in pregnancy. A comparison exercisers and non-exercisers. Aus $\mathrm{N} Z$ J Obstet Gynecol. 2000; 40(4):442-447.

23. Chang SR, Chao YM, Kenney NJ. I am a woman and I'm pregnant: body image of women in Taiwan during third trimester of pregnancy. Birth. 2006;33(2):147153. doi: 10.1111/j.0730-7659.2006.00087.x.

24. Smith SA, Hulsey T, Goodnight W. Effect of obesity on pregnancy. J Obstet Gynecol Neonatal Nurs 2008;37(2):176-184. doi: 10.1111/j.15526909.2008.00222.x.

25. Nierop A, Wirtz PH, Bratsikas A, Zimmermann R, Ehlert U. Stress-buffering effects of psychosocial resources on physiological and psychological stress response in pregnant women. Biol
Psychol 2008;78(3):261-268. doi: 10.1016/j. biopsycho.2008.03.012.

26. Leddy MA, Jones C, Morgan MA, Schulkin J. Eating disorders and obstetric-gynecologic care. J Womens Health 2009;18(9):1395-1401. doi:10.1089/ jwh.2008.1183.

27. Rofe Y, Blittner M, Lewin I. Emotional experience during the three trimesters of pregnancy. J Clin Psychol. 1993;49(1):3-12.

28. Huang HC, Wang SY, Chen CH. Body image, maternalfetal attachment, and choice of infant feeding method: a study in Taiwan. Birth. 2004;31(3):183-188. doi: 10.1111/j.0730-7659.2004.00303.x.

29. Liabsuetrakul T, Vittayanont A, Pitanupong J. Clinical applications of anxiety, social support, stressors, and self-esteem meaured during pregnancy and postpartum for screening postpartum depression in Thai women. J Obstet Gyneacol. 2007;33(3):333-340. doi: 10.1111/j.1447-0756.2007.00532.x.

30. Kumcagiz H. Pregnant women, body image and selfesteem according to the examination of some of the variables. Int J Hum Sci. 2012;9(2):691-703.

31. Babacan Gumus A, Cevik N, Hataf Hyusni S, Bicen S, Keskin G, Malak AT. [Characteristics associated with self-esteem and body image in pregnancy]. Anatol J Clin Investig. 2011;5(1):7-14.

Copyright $(2015$ The Author(s); This is an open-access article distributed under the terms of the Creative Commons Attribution License (http://creativecommons.org/licenses/by/4.0), which permits unrestricted use, distribution, and reproduction in any medium, provided the original work is properly cited. 